\title{
Práticas e eventos de letramentos no contexto de uma disciplina na modalidade semipresencial
}

\author{
Kariny Cristina Souza Raposo*
}

\begin{abstract}
Resumo
Assumindo a perspectiva dos estudos sobre letramento, a partir de uma abordagem social, conforme os Novos Estudos sobre Letramento - New Literacy Studies - (STREET, 2012, 2010, 2007; BARTON; HAMILTON, 1998, 2000, 2005), o presente trabalho descreve as práticas e os eventos de letramento ocorridos na disciplina de Leitura e Produção de Textos, ofertada na modalidade semipresencial nos cursos de graduação em Direito, Administração e Engenharia Civil, em um Centro Universitário do interior de Minas Gerais. Considerando, ainda, que os eventos de letramento apresentam o texto como elemento central na mediação das interações, parte-se de uma perspectiva textualmente orientada, ou seja, a partir da análise dos principais textos com os quais os estudantes lidam, levando em conta o gênero fórum, objetivou-se evidenciar as peculiaridades das práticas e eventos de letramento no ambiente acadêmico, no contexto específico da referida disciplina. O resultado da análise apontou para o fato de que, embora o fórum não gere uma discussão de fato, como é o seu propósito, contribui para a inserção dos alunos nas atividades acadêmicas, o que possibilita que eles se engajem nas práticas típicas da academia.

Palavras-chave: Práticas de letramentos. Eventos de letramento. Educação a distância. Disciplina semipresencial. Gênero fórum.
\end{abstract}

Recebido em:30/04/2017

Aceito em:25/09/2017

* Doutora em Língua Portuguesa e Linguística - PUC Minas. Professora de Leitura e Produção de Textos do UNIFEMM - Centro Universitário de Sete Lagoas. 


\section{Introdução}

O papel da linguagem na sociedade contemporânea tem ganhado contornos cada vez mais complexos. Com os avanços tecnológicos, tornou-se possível diminuir as fronteiras e distâncias espaçotemporais, o que obviamente, trouxe consequências para as relações sociais, bem como para o modo como as interações se estabelecem.

Nesse contexto, a Educação a Distância (EaD) vem se consolidando e ganhando espaço em universidades e instituições, dado o seu potencial para atender com rapidez às demandas da sociedade por atualizações constantes de conhecimentos. Além disso, outros fatores vêm contribuindo para que a EaD se estabeleça, de vez, como uma modalidade de ensino/aprendizagem, dentre os quais: a) a percepção, por parte do Governo Federal, de que a EaD pode ser uma alternativa para a ampla demanda social por democratização do ensino, preceito estampado na LDBEN - Lei de Diretrizes e Bases da Educação Nacional - (Lei 9.394/96, BRASIL); b) a necessidade das organizações de capacitarem seus profissionais, de forma contínua, com vistas à otimização de processos e ganhos de produtividade; e c) a demanda crescente do mercado de trabalho por profissionais cada vez mais qualificados, com domínios específicos em diferentes áreas do conhecimento.

Os ambientes educacionais, então, precisam levar em conta esses aspectos, a fim de que o processo de aprendizagem envolva atividades de leitura, escrita e oralidade que façam parte não apenas do universo escolar dos sujeitos, mas também de sua vida cotidiana. No entanto, boa parte das pesquisas, nesse campo de estudos, tem enfatizado questões relativas ao modelo pedagógico (MORAN, 1994; PIMENTEL, 1995; PRETI, 1996) ou questões relativas à performance das diferentes plataformas tecnológicas disponíveis para o gerenciamento do ensino a distância (MAURER, 1997; HORTON, 2000, LEE; OWENS, 2000).

Exatamente por isso, torna-se pertinente investigar as práticas vigentes no ambiente acadêmico a partir de um conceito de múltiplos letramentos, conforme perspectiva delineada pelos Novos Estudos sobre Letramento (LEA; STREET, 1998; STREET, 2010, 2012, 2014), que propõem uma abordagem social para esses estudos. Sob esse enfoque, Barton e Hamilton (2000) definem eventos de letramento como "atividades em que o letramento tem o seu papel", e acrescentam: eventos "são episódios observáveis que emergem das práticas e são moldados por 
elas" (BARTON; HAMILTON, 2000, p. 8). Assim, as práticas e os eventos de letramento tornam-se fundamentais para compreendermos o letramento como um fenômeno social.

Então, a fim de proceder a uma breve descrição sobre o letramento, que se torna ainda mais complexo quando mediado pelas Tecnologias Digitais da Informação e Comunicação (TDIC), objetivou-se descrever as particularidades das interações das práticas e eventos de letramento no ambiente acadêmico no contexto específico de uma disciplina de Leitura e Produção de textos ofertada na modalidade semipresencial. Espera-se, dessa forma, contribuir para uma melhor compreensão sobre o gênero fórum e sua função no contexto em que se realiza, além de refletir sobre o seu papel na construção do letramento dos estudantes.

Os dados foram obtidos por meio da observação do fórum da mencionada disciplina, que foi ofertada no segundo semestre de 2016. A escolha pelo fórum se deu pelo fato de ele se apresentar como um espaço adequado para o desenvolvimento de uma disciplina semipresencial, pois permite um tipo de interação que pode contribuir para a construção coletiva do saber, além de se configurar como uma poderosa interface para se proceder à prática avaliativa, por promover o diálogo, $\mathrm{o}$ que, por sua vez, possibilita uma avaliação na dimensão dialógica.

Nesse sentido, uma das principais características dos Novos Estudos sobre Letramento consiste na mudança de foco quando se trata de entender a escrita: do texto para as práticas sociais, ou seja, busca-se compreendê-lo a partir das práticas sociais e culturais em que a produção de textos acadêmicos se situa.

Apenas com fins de organização, dividiu-se este trabalho nas seguintes seções: Práticas e eventos de letramento no contexto da educação a distância; O gênero fórum e a semipresencialidade; ${ }^{1}$ Aspectos metodológicos das análises textuais; Análises e considerações finais.

\section{Práticas e eventos de letramento no contexto da educação a distância}

O sistema educacional brasileiro, desde o processo de alfabetização até o ensino superior, sempre se preocupou com aspectos relativos à leitura, à compreensão e à escrita de textos. Entretanto, várias pesquisas, a partir das duas últimas

1 Embora não seja o objetivo principal desta seção, sempre que possível, serão retomados conceitos para fundamentar os exemplos apresentados. 
décadas, apontam a deficiência de compreensão e o escasso hábito de leitura entre estudantes universitários. Há de se considerar, ainda, que, ao ingressar na faculdade, o estudante se depara com as próprias limitações e, tentando sanar essas lacunas, passa a buscar alternativas, nem sempre produtivas, que minimizem suas deficiências. Diante disso, verifica-se, dentro da experiência do ensino superior, a necessidade de propostas de ensino e práticas de letramento que permitam a esse alunado resultados concretos em seu exercício de leitura e escrita para que se alcance o nível desejado.

Esse cenário tem resultado em pesquisas na área dos letramentos acadêmicos (STREET, 2010; LILLIS, 1999, 2003, LEA; STREET, 2006) e na busca por um entendimento crítico das práticas de escrita nas universidades e seus significados, que abarcam diferentes contextos e campos do conhecimento. Se, por um lado, os trabalhos intencionam sanar lacunas identificadas no meio acadêmico, chegamos a um momento em que não há como tratar dos letramentos acadêmicos sem abordar as tecnologias digitais. Há a necessidade de se estudarem práticas letradas em concomitância com as digitais, posto que as TDICs têm invadido a academia, quer pelos alunos, pelos professores ou mesmo em práticas institucionais, de modo geral (LEA; JONES, 2011).

À luz desse quadro, para a discussão aqui proposta, os conceitos de práticas de letramento e o de eventos de letramento tornam-se importantes, pois permitem uma melhor compreensão do fenômeno do letramento e das práticas sociais que o envolvem (LÊDO, 2013). Sob essa ótica, no Brasil, pesquisadores em Ciências da Linguagem recorrem a trabalhos de Street (1998; 2010; 2012; 2014), na investigação de práticas sociais de leitura e escrita distintas das de um mero processo de (de)codificação da língua. O mesmo autor posiciona a discussão atual sobre letramento considerando que essas práticas são variadas e complexas, assim como seus contextos. Sob esse viés, falar em práticas de letramento amplia o seu conceito, destacando o caráter sócio-histórico e dinâmico do termo.

As práticas de letramento dizem respeito às práticas sociais e concepções de leitura e escrita de uma comunidade (STREET, 2012). Assim, modelam os eventos de letramento, oferecendo sentidos próprios aos usos da leitura e escrita pelas pessoas nas diversas situações comunicativas. Essas práticas, assim como as demais práticas sociais, estão intrinsecamente relacionadas às estruturas sociais mais amplas, o que reflete o caráter ideológico que as permeia (STREET, 2012). São, portanto, as normas, os direitos, os deveres, os papéis sociais assumidos, 
as relações estabelecidas, bem como as atribuições de valores realizadas pelos participantes da interação, ao longo do tempo, em relação às práticas de leitura e escrita disseminadas na comunidade. Tais práticas são visíveis a partir dos eventos de letramento, que são definidos por Barton e Hamilton (1998) como "atividades em que a escrita tem papel fundamental para a interação e por meio dela as práticas de letramento vigentes naquele contexto específico se tornam visíveis" (BARTON; HAMILTON, 1998, p. 12) e, ainda, conforme esses autores, as práticas de letramento são atividades regulares repetidas e observáveis em eventos mediados por textos escritos.

Hamilton (2000) também descreve o caráter abstrato das práticas de letramento, que são localizáveis apenas através dos eventos de letramento. $\mathrm{O}$ autor aponta os elementos não visíveis que podem ser inferidos a partir dos eventos a que estão associados, a saber: a) os participantes ocultos, ou seja, as outras pessoas ou grupos que estão envolvidas nas relações sociais de produção, interpretação, circulação e qualquer outra forma de regulação de textos escritos; b) o domínio prático no qual o evento tem lugar e de onde retira o seu sentido e propósito social, todos os demais recursos trazidos para a prática de letramento, incluindo valores não materiais, entendimentos, modos de pensar, de narrar, habilidades e conhecimento; e c) as rotinas estruturadas e trilhas que facilitam ou regulam as ações, como as regras de elegibilidade, a definição de quem pode ou não se engajar em determinadas atividades, ou quem pode ou não realizar certas ações. Então, por meio da análise dos eventos de letramento, torna-se possível analisar os textos como vestígios da prática social subjacente, bem como das ideologias, crenças e valores enraizados.

Outra discussão proposta por Barton e Hamilton (2005) está relacionada às características do conceito de práticas e eventos de letramento. Os autores destacam como pontos fundamentais: a) as práticas de letramento são perceptíveis através dos eventos de letramento e estes se constituem como unidades básicas de análise; b) os eventos de letramento são mais específicos e decorrem de práticas de letramento; c) as práticas e os eventos de letramento estão localizados em estruturas sociais; d) práticas e eventos de letramento são históricos, situados em um tempo e lugar específicos; e) práticas e eventos de letramento são dinâmicos e conflituosos; f) as práticas e os eventos de letramento são multimodais; g) os eventos de letramento podem ser recontextualizados. 
Desse ponto de vista, por conseguinte, ressalta-se que, para este trabalho, consideram-se apenas os letramentos relacionados com práticas de leitura e escrita dos textos, visto que, mesmo que as práticas orais sejam relevantes, na modalidade a distância elas são quase inexistentes. Por fim, ao se assumir que o texto é central nos eventos de letramento, torna-se oportuno relacionar a noção de letramento à de gênero textual.

\section{0 gênero fórum e a semipresencialidade}

A Portaria $\mathrm{n}^{\mathrm{o}} 4.059,{ }^{2}$ de 10 de dezembro de 2004, trouxe para as instituições de Ensino Superior - IES - a possibilidade de oferecerem até $20 \%$ de suas disciplinas na modalidade semipresencial de cursos já reconhecidos. Também, de acordo com essa portaria, as disciplinas semipresenciais caracterizam-se como atividades didáticas e unidades de ensino/aprendizagem centradas na autoaprendizagem, com a mediação de recursos didáticos, organizados em diversos suportes de informação que empreguem tecnologias de comunicação remota sob a tutoria de professores qualificados, com carga horária para momentos presenciais e a distância.

A semipresencialidade é, então, uma proposta que reflete uma tendência educacional nas instituições de educação superior do país e uma aposta na ampliação das possibilidades de interação no fazer pedagógico. Por isso, o aperfeiçoamento dessa modalidade nos cursos de graduação está vinculado à constante reflexão acerca de tal iniciativa, com participação da instituição, dos docentes e dos discentes, demandando, dessa forma, pesquisas e avaliações em relação à qualidade da modalidade como um todo.

$\mathrm{Na}$ instituição objeto deste estudo, as disciplinas semipresenciais começaram a ser ofertadas no segundo semestre de 2012, tendo como suporte o software Moodle que, além de ser um sistema de código aberto (livre), possibilita o gerenciamento de cursos a partir do qual a IES construiu o seu Ambiente Virtual de Aprendizagem (AVA). O Moodle oferece vários recursos pedagógicos, entretanto, para este trabalho, optou-se pelo fórum, que, nesta IES, apresenta-se de três modos distintos: fórum de dúvidas, participativo e avaliativo. Tal escolha se deveu ao

2 Essa portaria foi revogada pela Portaria $n^{\circ} 1.134$, de 10 de outubro de 2016, estabelecendo que não há mais necessidade de aguardar reconhecimento dos cursos para a oferta dos $20 \%$, desde que a IES tenha um curso reconhecido. 
fato de ser este o principal meio de interação entre os professores, os estudantes e o conteúdo da disciplina. Tanto é assim que estudos têm sido realizados com o intuito de explicar as características desse gênero a partir de diferentes perspectivas: Lêdo (2011), que aborda as características do fórum à luz da Teoria Dialógica do Discurso; Bezerra (2011), cujos estudos investigam como ocorre o uso da linguagem em fóruns educacionais; Scavazza (2010) que, do ponto de vista temático, composicional e estilístico, estuda o fórum como gênero emergente a partir da teoria bakhtiniana, são alguns exemplos.

Então, o fórum é assumido, neste trabalho, como um gênero digital que reúne as opiniões de uma comunidade discursiva (PAIVA; RODRIGUES JR., 2004) sobre um tópico específico, sendo caracterizado por seu caráter interativo e dialógico. São compostos por três elementos fundamentais: conteúdo temático, estilo e construção composicional (BAKHTIN, 2002). Dessa forma, o fórum também é considerado um dos gêneros emergentes (MARCUSCHI, 2005) que surgiram com o desenvolvimento da internet e das tecnologias de comunicação. Apresenta-se na forma de um debate de ideias, além de ser tipicamente assíncrono, o que garante maior flexibilidade aos participantes. Diferentemente dos fóruns abertos, que podem ser acessados por todos os usuários da rede, os educacionais têm seu acesso restrito aos alunos matriculados naquele curso ou disciplina e respectivos professores.

Para Lêdo (2013), dois aspectos merecem destaque para a caracterização do fórum: o primeiro é que, por ele acontecer em meio digital, há a incorporação de determinadas características como os hipertextos, principalmente em forma de links (exemplo 1).

\section{Exemplo 1 - (fórum de dúvidas): Aluno disponibilizando link para os colegas.}

Mensagem postada em 04/10/2016.

Re: Fórum de Dúvidas do Módulo I

$\ominus$ por 032226

terça, 4 Out 2016, 09:30)

Boa tarde a todos! Pelo que entendi, jargão é um código linguistico próprio de um grupo profissional ou sociocultural. A giria é chamada de jargão quando é restrita a uma profissão. Leiam alguns artigos muito interessantes a respeito acessando o link http://www1.folha.uol.com.br/folha/sinapse/ult1063u468.shtml. Abraços.

Fonte: AVA

Além da questão apontada por Lêdo (2013), esse exemplo evidencia que as práticas e os eventos de letramento são multimodais, conforme pontuado por Barton e Hamilton (2005): “o letramento sempre coexiste com uma variedade de 
outros modos de construção de significados, em especial construção de significado visual, e o letramento é apenas uma parte de uma gama de recursos semióticos" (BARTON; HAMILTON, 2005, p. 6)

$\mathrm{O}$ segundo aspecto relaciona-se à esfera de atividades acadêmicas à qual o fórum está atrelado. Como se trata de um ambiente aberto aos demais participantes do curso, percebe-se que há uma forte preocupação, por parte dos alunos, em privilegiar a norma padrão, o que, muitas vezes, inibe a participação dos discentes que receiam não atender a esse critério (ainda que, de modo eventual, nos fóruns analisados, note-se o uso por professores e alunos de abreviações como abs, bjus etc.).

Para Barton e Hamilton (2005), as práticas de letramento refletem as práticas sociais subjacentes. No entanto, não há a separação explícita das práticas de cada esfera, ou seja, há uma sobreposição das práticas de letramento, e o que se aprende em um domínio pode ser adaptado em novo contexto, de forma que, considerando a esfera acadêmica, os estudantes partem da sua experiência com práticas de outros domínios, de práticas mais ou menos informais com as quais tiveram contato em diferentes ambientes para compreender e participar de práticas de letramento acadêmico.

Sobre a forma composicional, os fóruns se apresentam como uma sequência de postagens que podem ser visualizadas de forma aninhada. A primeira mensagem contém o título do fórum, a data e a indicação da atividade proposta. Na sequência, o professor/tutor, ${ }^{3}$ conforme denominação adotada pela IES estudada, dá as boasvindas e incita à participação (exemplos $2 \mathrm{a}$ e $2 \mathrm{~b}$ ). Isso implica dizer que o fórum possui vários autores, o que, por consequência, o constitui como gênero cuja escrita, a princípio, deve ser interativa/colaborativa.

\section{Exemplo 2a - Forma de apresentação do fórum}

Re: Fórum de Dúvidas do Módulo

$\odot$ por 001505

quinta, 21 Jul 2016, 13:49

Olá pessoal, boa noite!

Meu nome é ! ' e estarei com vocês nesta disciplina tendo como nosso ponto de encontro este espaço!

Aqui, vamos conversar, tirar dúvidas, trocar conhecimentos e nos aproximar para que nosso aprendizado seja conjunto. Por

isso, quero saber um pouco mais sobre você!

Qual o seu nome? Idade? Já tem alguma graduação? O que você espera desta disciplina? Já teve alguma experiência com

cursos a distância?

Fonte: AVA

3 Na instituição, foco deste estudo, o professor da disciplina assume também a função de tutor no AVA. Por isso, adotou-se a denominação professor/tutor. 


\section{Exemplo 2b - Forma de apresentação do fórum}

Re: Fórum de Dúvidas do Módulo I

๑ por 031162

- quarta, 17 Ago 2016, 10:40

Bom dia, meu nome é

, trabalho na área elétrica de manutenção e montagem industrial. Sobre essa disciplina, acredito

ser importante pois, tenho visto nas empresas problemas constantes na área técnica e principalmente na comunicação interna, problemas ocasionados muitas vezes por não possuirem um padrão a ser seguido. Conhecer técnicas e padrōes a serem seguidos, ou conceitos para desenvolvimento dessas normas,é o quê pretendo obter nessa disciplina. Minha formação é de cursos técnicos, realizados nas unidades do Senai e treinamentos especificos nas empresas onde trabalhei.

\section{Fonte: AVA}

A cada intervenção, aparecem o número da matrícula do participante (1), seu nome (2), a data e a hora da postagem (3). A seguir, acrescenta-se o corpo da mensagem com o conteúdo principal (4) (exemplo 3). Outra característica dos fóruns está relacionada aos prazos determinados para sua realização. Cada fórum de dúvidas tem a duração condizente com o módulo a que se refere, em média 3 meses. Já os fóruns temáticos e avaliativos duram cerca de 15 dias. Após os períodos estabelecidos, os fóruns são encerrados e os alunos ficam impossibilitados de participar.

\section{Exemplo 3 - Layout de apresentação dos fóruns}

Re: Fórum de Dúvidas do Módulo I

$\Phi$ por $031162 \quad 2$-segunda, 5 Set 2016,12:25 3

Boa tarde,

4

a lingua portuguesa é de dificil entendimento, tanto para ler ou escrever. Quero obter conhecimentos para diminuir essa enorme

4 dificuldade que é "escrever correto", pois, se faz necessário devido as atividades profissionais e pessoais.No trabalho, os relatórios hoje sẫo mais complexos e, em casa, tenho filhos que sempre me perguntam a forma correta de escrever.

Fonte: AVA

\section{Aspectos metodológicos das análises textuais}

A disciplina de Leitura e Produção de Textos, objeto desta análise, possui 40 horas e seis encontros presenciais ao longo do semestre. É dividida em três módulos e cada um prevê a realização de um fórum avaliativo, um fórum de dúvidas e um fórum participativo. A diferença entre os dois últimos reside no fato de que, enquanto o fórum participativo é realizado a partir de uma problematização específica, o de dúvidas não apresenta problematização, ficando os alunos livres para tirarem dúvidas e/ou tecerem comentários que estejam vinculados ao conteúdo 
da disciplina. Já o fórum avaliativo acontece um vez ao longo do semestre e obedece a critérios avaliativos preestabelecidos. Os encontros presenciais, por sua vez, acontecem um vez ao mês e são destinados, inclusive, para as provas presenciais, conforme exigência do MEC.

$\mathrm{Na}$ instituição, há três professores/tutores da disciplina de Leitura e Produção de Textos. Entretanto, para este trabalho, foram observadas as interações de apenas um desses profissionais, que poderá ser identificado pelo número de matrícula 001505 .

Com relação ao corpus, foram selecionadas 13 postagens que representam momentos de dialogismo nas três naturezas do fórum e, por isso, possibilitam-nos uma melhor compreensão das especificidades do gênero. Uma análise qualitativa ${ }^{4}$ dos dados foi realizada a partir de uma abordagem de cunho etnográfico ${ }^{5}$ e os participantes foram os 92 alunos matriculados nos cursos de graduação em Direito, Administração e Engenharia Civil. Destaca-se que, como a disciplina de Leitura e Produção de Textos é componente curricular do núcleo básico comum, é habitual que a enturmação seja feita com alunos de cursos distintos. ${ }^{6}$

Assim, considerou-se importante compreender se o fórum foi utilizado de maneira a atingir seus propósitos comunicativos, refletir sobre o papel desse gênero para o desenvolvimento do letramento do estudante, bem como relacionar os exemplos do corpus com a percepção dos usuários sobre esse gênero.

\subsection{Análises das práticas}

Uma questão importante relacionada à função do professor / tutor diz respeito à sua participação no fórum que, além de contínua, deve se pautar por contribuições que estimulem os estudantes a interagirem. O "silêncio" do professor/tutor

4 Ao dizer "qualitativa", refiro-me a "um conjunto de técnicas de investigação, como a observação participante [...]. A análise qualitativa fundamenta a investigação em dois sentidos: permite ajustar as expectativas que os investigadores têm sobre determinado problema social à sua realidade, $[\ldots]$ e apreender mais de perto determinadas realidades sociais que outras técnicas de investigação não permitem, como as que derivam da análise quantitativa" (Disponível em: https://www.infopedia. $\mathrm{pt} /$ \$analise-qualitativa).

5 Vale ressaltar que "etnográfico" apresenta diferentes acepções. No presente trabalho, estou considerando "abordagem etnográfica" de maneira ampla, no sentido de inserção como observadora das práticas de ensino/aprendizagem ocorridas no AVA.

6 Depois de feita a enturmação e de realizada a matrícula no AVA, o professor / tutor não tem como identificar a que curso o aluno pertence. 
representa "um poderoso feedback negativo que pode desestimular a interação e causar o abandono de fóruns, do curso ou disciplina" (PAIVA; RODRIGUES JR., 2004, p. 180). Relacionados a isso, os exemplos 4, 5 e 6 demonstram a preocupação do professor / tutor da disciplina em tela de se "fazer" presente:

Exemplo 4 - (fórum de dúvidas): Professor da disciplina dando orientações sobre o conteúdo a ser estudado. Mensagem postada em 17/08/2016

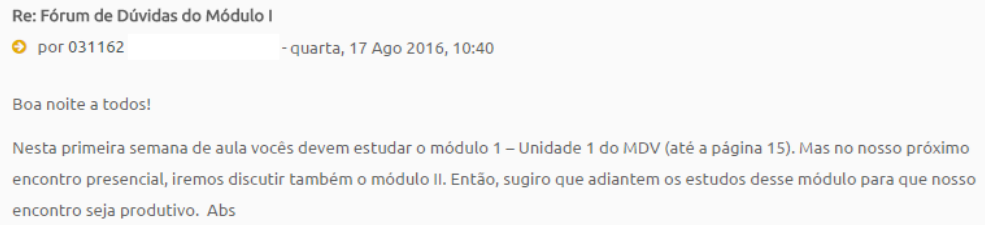

Fonte: AVA

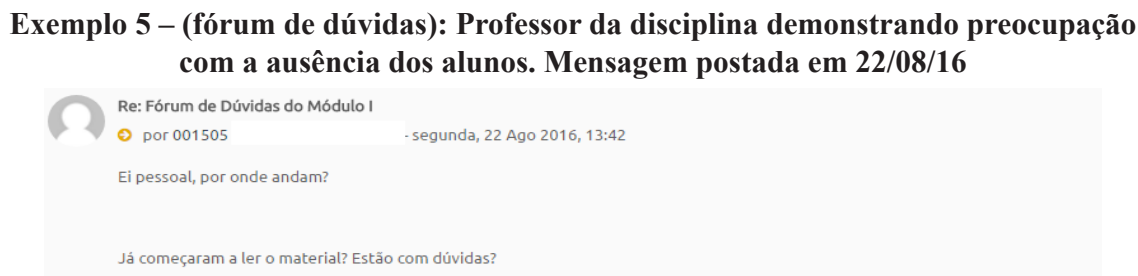

Fonte: AVA

Exemplo 6 - (fórum de dúvidas): Professor da disciplina buscando a interação com os alunos. Mensagem postada em 25/08/2016

Re: Fórum de Dúvidas do Módulo I

() por 001505

- quinta, 25 Ago 2016, 12:10

Queridos alunos,

estão com alguma dificuldade no estudo dos materiais?

\section{Fonte: AVA}

Observa-se que, em suas postagens, o docente busca a interação com os alunos e, dessa forma, fomenta um ambiente social amigável, essencial à aprendizagem a distância. Sobre isso, Palloff e Pratt (2002) ressaltam que, ao demonstrar interesse pelo outro, a partir dos comentários e da participação ativa, o professor/tutor pode ajudar a criar laços e fortalecer ambientes de confiança e participação. Essa 
postura do profissional condiz, ainda, com o pensamento de Barton e Hamilton (1998), para os quais as práticas de letramento são atividades regulares, repetidas, observáveis em eventos mediados por textos escritos (grifos meus).

Os mesmos autores (2005) comentam que se torna necessário observar as práticas a fim de perceber questões que envolvam relações de poder e hierarquia institucional. Além disso, estão permeados por questões ideológicas e isso influencia a constituição das práticas, ou seja, para a compreensão das práticas de letramento, é necessário olhar para as formas de organização dos papéis assumidos dentro das estruturas sociais.

Corroborando o pensamento de Lêdo (2013), outro aspecto relevante, no que diz respeito à caracterização do fórum, está relacionado à esfera acadêmica. Esse ambiente, além de exercer influência sobre o grau de formalidade, conforme já mencionado, salienta a utilização de citações para embasamento teórico da intervenção, bem como a necessidade da referência adequada às fontes consultadas (Exemplo 7).

Exemplo 7 - (fórum avaliativo): Os alunos tinham que discutir sobre os limites do
humor e a liberdade de expressão. A mensagem abaixo foi postada em 30/08/2016 (destaque meu)

Re: Forum Avaliativo Modulo II Unidade 1 - Discussâo de tema "O humor deve ter limites ou vale tudo em nome da liberdade de expressāo?"

$\odot$ por 034405

- terça, 30 Ago 2016, 08:54

O humor deve conter limites sim.

Nos último anos, elevaram-se consideravelmente o número de conflitos que abrangem a relação de humor, preconceitos e esteriótipos. No documentário "O riso dos outros " fica explícito o fato do humor baixo ser mais fácil de tirar os risos da plateia,onde os comediantes ridicularizam em suas piadas as mulheres, gays, gordos, negros, deficientes físicos,etc. No entanto a realidade social é preconceituosa, na qual os preconceitos arraigados na sociedade fornecem o material necessário para o humor, e esse é explicado com o simples argumento: "É SÓ UMA PIADA!". Portanto, observa-se comum esse tipo de humor inserido na sociedade pelo fato dos comediantes não terem a capacidade de criarem um humor que seja instigante pois exige engenhosidade,esforço e superação do senso comum. É como diz Jean Wyllys (deputado federal) no documentário de Pedro Arantes "O riso dos outros ": "Existem outras formas de fazer humor. Existem outras maneiras de fazer rir sem humilhar os outros. Alguém de talento, de verdade, consegue fazer isso. E mesmo quando voce traz essas minorias para a piada, ela não precisa ser, necessariamente, humilhando a pessoa."

(http://wnw.cartamaior.com.br/?/Editoria/Cultura/O-riso-dos-outros-Ha-limites-para-o-humor-/39/32668)

\section{Fonte: AVA}

Para participar de forma significativa, o aluno precisa pesquisar o assunto, estudar o material da disciplina, elaborar a resposta, ler as respostas dos outros colegas e os comentários do professor; ou seja, precisa efetuar uma série de ações que envolvem diversos textos, o que contribui para a aprendizagem no evento de letramento no fórum. Barton e Hamilton (2005) afirmam que para "compreender 
as práticas de letramento particulares, precisamos olhar além das relações sociais observáveis para a mais ampla padronização social" (BARTON; HAMILTON, 2005, p. 4), dito de outra forma, é necessário atentar para as formas de organização dos papéis assumidos dentro das estruturas sociais.

Como prática de avaliação, o fórum se mostrou, até certo ponto, intimidador da interação. Nessas atividades, são especificados critérios de avaliação que orientam de forma indireta a utilização do gênero, mas, percebe-se que por medo de errarem, talvez, os alunos se limitam a responder a problematização proposta e/ou, muitas vezes, a copiar trechos da internet (exemplos 8 a e b).

Exemplos $8 \mathrm{a}$ e b (fórum avaliativo) - Tomando como base uma carta comercial disponibilizada pelo professor/tutor, os alunos foram orientados a redigir um parágrafo argumentativo respeitando o seguinte enunciado: Observe a linguagem empregada neste gênero específico. A linguagem em estudo apresenta quais características? Defenda suas hipóteses para a utilização dessa linguagem, associando-as à função da carta comercial.

Critérios de avaliação:

- Clareza na exposição das ideias;

- Cumprimento das normas da ABNT para citações e referências;

- Cumprimento do solicitado no enunciado;

- Interação com os colegas enriquecendo seus comentários;

- Posicionamento embasado nos estudos realizados na disciplina.

\section{Exemplo 8a - Resposta de aluno à questão proposta}

Re: Fórum Avaliativo Modulo II Unidade 2

๑ por 001505

- terça, 18 Out $2016,20: 59$

Oi pessoal, bom dia!

No nosso último encontro presencial, começamos a falar sobre democracia e suas implicações para o atual cenário politico brasileiro. Percebi o quanto vocês ficaram animados com a conversa. Com base nisso, proponho o seguinte tema para nossa discussão aqui no fórum: a) "Quais são os problemas que mais preocupam os brasileiros atualmente? "b) "O que os brasileiros valorizam no Brasil? " c) "Como eles avaliam a importância da politica? " Apresente seu ponto de vista sobre os tópicos abordados. Quero muito saber qual é a opiniăo de vocês. Estou ansiosa para lê-los!

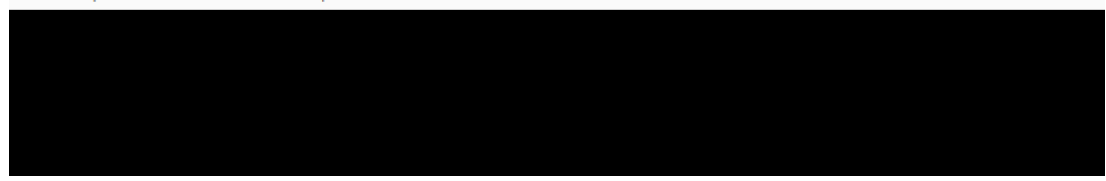

Fonte: AVA 


\section{Exemplo 8b - Tentativa de interação com postagem anterior (destaques meus)}

Re: Fórum Avaliativo Modulo III Unidade 2

$\odot$ por 033361

sexta, 28 Out $2016,00: 38$

Concordo com a colega, pois a carta contém todos os elementos e informações de uma carta comercial como linguagem objetiva,clara e padrão omo bem apontado pela

Fonte: AVA

A partir da observação sistemática do fórum avaliativo, pode-se postular certo desconforto por parte dos alunos em relação à avaliação, diferentemente do que acontece com os fóruns de dúvidas e temáticos. Tal percepção se torna mais consistente ao se comparar as interações do fórum avaliativo com as dos outros fóruns, que não têm esse caráter. A postagem do estudante, no exemplo 8a, limita-se a responder à questão proposta de modo superficial, não atendendo ao solicitado na atividade. Na mesma linha, embora o aluno do exemplo $8 \mathrm{~b}$ esboce uma interação com a postagem do aluno $8 \mathrm{a}$, ele se restringe a reproduzir sua fala, acrescentando poucas informações.

Outra particularidade observada nos fóruns foram as postagens impessoais. Poucas vezes, perceberam-se intervenções direcionadas ao professor, conforme demonstrado nos exemplos 9,10 e 11 .

Exemplo 9 - (fórum avaliativo): Postagem do professor sobre atividade a ser realizada. Mensagem postada em 18/10/2016

Re: Fórum Avaliativo Modulo II Unidade 2

$\odot$ por 001505

-terça, 18 Out $2016,20: 59$

Oi pessoal, bom dia!

No nosso último encontro presencial, começamos a falar sobre democracia e suas implicações para o atual cenário politico brasileiro. Percebi o quanto vocês ficaram animados com a conversa. Com base nisso, proponho o seguinte tema para nossa discussão aqui no fórum: a) "Quais são os problemas que mais preocupam os brasileiros atualmente? "b) "O que os brasileiros valorizam no Brasil? " c) "Como eles avaliam a importância da politica?" Apresente seu ponto de vista sobre os tópicos abordados. Quero muito saber qual é a opiniăo de vocês. Estou ansiosa para lê-los!

Fonte: AVA 


\section{Exemplos 10 e 11 - (fórum avaliativo): Intervenções dos alunos sem direcionamento a um receptor específico. Mensagens postadas em 18/10/2016 \\ Re: Fórum de Avaliativo Modulo II Unidade 2 \\ ๑) por 029583 \\ terça, 18 Out 2016, 22:01

\begin{abstract}
Nos dias de hoje, os brasileiros passam por uma das piores crises econômica que já assolou o pais. Devido o aumento continuo da taxa
Essa situaçăo que a população está submetida tende a extinguir o sentimento de patriotismo dos brasileiros que há muito tempo
\end{abstract} de desemprego, aumento dos preços de produto essenciais, como alimentos, e o sentimento de abandono que a meu ver é o principal problema que atinge a população, principalmente a mais carente, que é atingida de forma severa. vem-se em desgaste, atualmente vemos que os cidadãos bem estruturados preferem, muitas vezes, recomeçar a vida em outros paises, do que esperarem o reerguimento da sua pátria já chamada outrora de amada. A população carente que infelizmente não tem muitas alternativas a não se agarrar em suas crenças e na esperança de um futuro melhor.}

A população esta cada vez mais descrente com a atuação politica do pais. Vemos verdadeiros circos armados para tratar de assuntos importantes para o bem estar da populaçâ,o, muitas vezes politicos despreparados, outros mercenários, verdadeiros versões antagônicas do famoso "Robin Hood", preocupados somente com quanto vão lucrar, trazendo uma vergonhosa imagem para a politica brasileira, não só para o mundo, mas para o seu povo que o mais prejudicado.

Fonte: AVA

Re: Fórum de Avaliativo Modulo II Unidade 2

๑ por 033366

- terça, 18 Out 2016, 23:03

Arualmente, a que mais preocupa as brasileiros è o desemprego, a faltra de oportunidade no mercado, conseguir emprego e também estudar, para aperfeiçoar e ter um borm trabalho. Nós brasileiras valorizamos muito ter um bom emprego; carro, casa, status, porder, ef não valorizamos as origens, onde nascemos como crescemos enfim.

Hoje em dia avaliam como péssimas pelos fatos vividas no Brasil devido a pollitica, mas também não fazem nada para melhorar, só sabem julgar e reclamar. A partir do momento em que tadas pensar em conjunto o cenário vai mudar

Fonte: AVA

Esses exemplos refletem, de certa forma, a tensão própria das relações sociais e mostram que o letramento pode ser conflituoso, ocorrendo dentro de um contexto cultural que, muitas vezes, leva em conta as questões de poder. Ainda nesse contexto, destaca-se o exemplo 12, a seguir, para ilustrar um caso raro, em que o estudante se dirige ao professor/tutor e propõe uma interação com o colega:

\section{Exemplo 12 - postagem de aluno propondo interação}

\section{Re: Fórum de Avaliativo Modulo II Unidade 2}

$\rightarrow$ por 032936

- terça, 18 Out 2016, 23:29

Boa noite professora! Esse assunto é bem oportuno mesmo! Estamos todos inseguros e como diss

\section{Fonte: AVA}

Outra possibilidade dos fóruns diz respeito à mudança de tópico, isto é, um aluno realiza uma postagem não condizente com o assunto que está sendo abordado (exemplo 13). 
Exemplos 13 - (fórum de dúvidas): mudança de tópico e intervenção do professor.

Mensagem postada em 10/10/2016

Re: Fórum de Dúvidas do Módulo II

๑ por 033254

segunda, 10 Out $2016,07: 24$

Oi professora, estou com uma dúvida sobre minha matricula no sistema. Você pode me ajudar? Não estou conseguindo abrir todas as materias.

\section{Fonte: AVA}

Nesse caso, a aluna insere uma questão que destoa do assunto tratado no fórum. A resposta do professor/tutor (exemplo 14), no entanto, aponta para a manutenção da configuração do gênero, contribuindo para a regulação do tema, bem como dos propósitos do gênero.

\section{Exemplo 14 - (fórum de dúvidas): professor contribuindo para a manutenção do}

\section{tema do fórum}

Re: Fórum Avaliativo Modulo III Unidade 2

○ por 001505

-terça, 18 out $2016,19: 33$

Oi João Pedro, posso te orientar a procurar o setor responsável por isso, ok? Da próxima vez que tiver qualquer dúvida técnica, envie-me por mensagem direta/e-mail, só para que a gente consiga manter o foco do fórum, tudo bem? Vou te auxiliar na

mensagem privada.

abs

Fonte: AVA

Torna-se importante ressaltar que a manifestação de um propósito comunicativo comum não implica, naturalmente, uma rigidez estrutural na construção do gênero fórum. A maleabilidade em si, traço constitutivo da produção e circulação dos gêneros, não invalida a sua identificação através de propósitos comunicativos específicos.

Porém, na versão inicial do conceito de propósito comunicativo, Swales (1990) sustenta a posição de que esse é o critério de maior importância no reconhecimento de gêneros e, ao definir gêneros, afirma que "o propósito comunicativo é um critério privilegiado que opera no sentido de manter o escopo do gênero, conforme concebido aqui, estreitamente ligado a uma ação retórica comparável" (SWALES, 1990, p. 58).

Assim, o conceito de propósito comunicativo, originalmente, é o critério privilegiado na definição de gênero e determina não somente a sua forma, mas 
também as escolhas relativas ao conteúdo e ao estilo. Isso quer dizer que o gênero se mantém focalizado em uma determinada ação retórica graças aos seus propósitos comunicativos.

\section{Palavras finais}

A partir das análises empreendidas, considera-se que as práticas e eventos de letramento no contexto da $\mathrm{EaD}$ evidenciam que o AVA se configura como um espaço a partir do qual ocorrem variados eventos de letramento que, no presente caso, incorporam as características do meio digital como, por exemplo, a prevalência de gêneros escritos sobre os orais. Ao acessar o AVA, o discente realiza várias ações (ler avisos, fazer pesquisas e leituras, elaborar sua postagem, dentre outros) que contribuem para a constituição de um evento de letramento tanto do ponto de vista linguístico-discursivo, quanto do reconhecimento das práticas de letramento típicas daquele ambiente.

A partir dessa constatação e tomando como objeto de análise os fóruns da disciplina de Leitura e Produção de Textos na modalidade semipresencial, observou-se que a forma como esse gênero é apresentado aos estudantes aponta para uma concepção dos modos de letramentos acadêmicos (LEA; STREET, 1998), na medida em que buscam a socialização do discente. Outro aspecto relevante apontado pelo estudo reside no fato de que o gênero aqui analisado "cria expectativa sobre qual é o papel assumido pelo indivíduo ao participar daquele evento" (LÊDO, 2013, p. 142). Assume-se, por exemplo, que é função do professor/tutor participar continuamente, incentivando, avaliando e mediando as postagens dos alunos. Cabe, ainda, a esse profissional regular as interações instruindo os participantes quanto aos propósitos, estrutura e funcionamento do gênero. Essas orientações são metadiscursivas, visto que ensinam sobre o gênero dentro do próprio gênero, possibilitando uma melhor compreensão sobre eventos de letramento dos quais os alunos participam (LÊDO; 2013). Por outro lado, é função dos estudantes participarem da discussão, posicionando-se criticamente e emitindo opinião fundamentada em leituras realizadas em relação ao que está sendo discutido

Sobre a interação, tão almejada nos fóruns, percebe-se que a formalidade, a impessoalidade e, possivelmente, a divergência de expectativas entre professores/ 
tutores e alunos sobre os procedimentos esperados para o gênero contribuem para que não ocorra uma discussão de fato. Isso se torna mais evidente nos fóruns avaliativos, cujo propósito, de modo geral, inibe a participação do aluno. Essa visão fundamenta-se ainda no conceito de que todo letramento é situado e corresponde a práticas sociais (STREET, 1984, 1998); conflitos de identidades muitas vezes são gerados devido às distintas bases culturais de alunos e docentes, o que pode ser esclarecido com a noção de que a escrita seria mais do que uma simples técnica, constituindo-se, portanto, em uma "maneira de se ver o mundo" (ZAVALA, 2010, p. 75).

Foi possível constatar, também, que, embora a modalidade a distância pressuponha autonomia de aprendizagem por parte dos alunos e de a maioria das orientações serem encontradas nos materiais didáticos e no AVA, na prática, o professor/tutor é o responsável por estimular a participação e a interação, além de otimizar o desenvolvimento do letramento acadêmico dos estudantes, na medida em que os insere nas atividades acadêmicas, possibilitando que eles se engajem nas práticas de letramentos típicas da esfera acadêmica. Por fim, os aspectos apontados por Barton e Hamilton (2005) demonstram a centralidade do letramento na sociedade contemporânea. 


\title{
Pratiques et événements de literacie dans le contexte de une discipline demi-presential
}

\begin{abstract}
Résumé
En envisageant le point de vue des études sur le literacie à partir d'une approche sociale, selon les Nouvelles Études sur le literacie - New Literacy Studies -, ce travail développe une recherche sur les pratiques et les activités de literacie travaillé dans la discipline Lecture et Production de Textes, qui sont offre en mode demi-ipresential dans les courses de baccalauréat en Droit, en Administration et Génie Civil. Considérant également que les activités de literacie présentent le texte comme un élément central dans la médiation des interactions, on partie d'une perspective textuellement orientée, qui est, de l'analyse des principaux textes avec lesquels les étudiants traitent, en tenant compte le genre "forum", on visait à étudier les particularités de las pratiques et des activités de literacie dans le contexte académique, dans le cadre spécifique de ladite discipline. Le résultat de l'analyse a souligné le fait que, bien que le forum ne génère pas une discussion de facto, comme c'est son but, il contribue à l'insertion des étudiants dans les activités académiques, ce qui leur permet de s'engager dans des pratiques académiques typiques.
\end{abstract}

Mots-clés: Pratiques de Literacie. Événements de literacie. Formation à distance. Discipline demi-presential. Genre forum.

\section{Referências}

BARTON, David; HAMILTON, Mary. Local literacies. London: Routledge, 1998.

BARTON, David; HAMILTON, Mary. Literacy, reification and the dynamics of social interaction. In: BARTON, David; TUSTING, Karin (Ed.). Beyond communities of practice: language, power and social context. Cambridge: Cambridge University Press, 2005. p. 14-35.

BERTOLIN, Júlio C. G; DE MARCHI, Ana Carolina Bertoletti. Instrumentos para avaliar disciplinas da modalidade semipresencial: uma proposta baseada em sistemas de indicadores. Avaliação, Campinas; Sorocaba, SP, v. 15, n. 3, p. 131146, nov. 2010.

BEZERRA, Benedito Gomes. Usos da linguagem em fóruns de EaD. Revista Investigações, Recife, v. 24, n. 2, p. 11-33, jul. 2011

BRASIL. Lei n. 9.394, de 20 de dezembro de 1996. Estabelece as diretrizes e 
bases da educação nacional. Brasília, 1996.

BOYD, William E.; CULLEN, Murray. A response to apparently low levels of numeracy and literacy amongst first year university environmental science students: a numeracy and literacy skills survey. International Research in Geographical and Environmental Education, v. 7, n. 2, p. 106- 121, 1998.

HENDERSON, Robyn; HIRST, Elizabeth. Reframing academic literacy: reexamining a short course for "disadvantaged" tertiary students. English Teaching: Practice and Critique, v. 6, n. 2, p. 25-38, 2006.

HORTON, William. Designing Web Based Training. New York: Wiley, 2000.

LEA, Mary. R.; STREET, Brian V. Student writing in higher education: an academic literacies approach. Studies in Higher Education, v. 23, n. 2, p. 157172, 1998. Disponível em: <https://goo.gl/WoZsgN.Pdf>. Acesso em: 7 jul. 2017. LEA, Mary R.; STREET, Brian V. The "academic literacies" model: Theory and applications. Theory into Practice, v. 45, n. 4, p. 368-377, 2006. Disponível em: <//goo.gl/s2fMEB.pdf>. Acesso em: 7 jul. 2017.

LEE, William W.; OWENS, Diana L. Multimedia-based Instructional Design. San Francisco: Jossey-Bass, 2000.

LÊDO, Amanda Cavalcante de Oliveira. Letramentos acadêmicos: práticas e eventos de letramento na educação a distância. Dissertação (Mestrado) Departamento de Letras, Universidade Federal de Pernambuco, 2013.

LILLIS, Theresa M. Ethonography as Method, Methodology, and 'Deep Theorizing': Closing the Gap Between Text and Context in Academic Writing Research. Written Communication, v. 25, n. 3, p. 353-388, 2012. Disponível em: $<$ http://wcx.sagepub.com/content/25/3/353.short $>$. Acesso em: 7 jul. 2017.

MAURER, Hermann. Necessary Ingredients of Integrated Network Based Learning Environments. In: WORLD ICDE CONFERENCE, $18^{\text {th }}$. Proceedings... Pennsylvania: Pennsylvania State University, 1997.

MATTOS, Carmem Lúcia Guimarães de. A abordagem etnográfica na investigação científica. In: MATTOS, Carmem Lúcia Guimarães de; CASTRO, Paula Almeida de (Org). Etnografia e educação: conceitos e usos [online]. Campina Grande: EDUEPB, 2011. p. 49-83.

MORAN, José Manuel. As Possibilidades das Redes de Aprendizagem, [S. d.] Disponível em: <http://goo.gl/X1IDRp.pdf>. Acesso em: 7 jul. 2017. 
PAIVA, Vera Lúcia Menezes de Oliveira e; RODRIGUES JÚNIOR, Adail Sebastião. Fóruns on-line: intertextualidade e footing na construção do conhecimento. In: MACHADO, Ida Lúcia; MELLO, Renato de (Org.). Gêneros: reflexões em análise do discurso. Belo Horizonte: Faculdade de Letras da UFMG, 2004. v. 1, p. 171-189.

PALLOFF, Rena M.; PRATT, Keith. O aluno virtual: um guia para trabalhar com estudantes online. Tradução de V. Fiqueira. Porto Alegre: Artmed, 2004.

PRETI, Oreste. Educação a distância: uma prática educativa mediadora e mediatizada. In: Educação a Distância: inícios e indícios de um percurso. Cuiabá: UFMT, 1996. p. 15-56.

PIMENTEL, Renato Lira. Gêneros textuais em fascículos digitais de EaD: apropriação e trabalho pedagógico. In: SIMPÓSIO DE HIPERTEXTO E TECNOLOGIAS NA EDUCAÇÃO, 4, Anais... Recife, 2012. Disponível em: $<$ http://goo.gl/6mhKWU>. Pdf. Acesso em: 7 jul. 2017.

SCAVAZZA, Carolina. Gêneros discursivos emergentes: o fórum na educação a distância. Dissertação (Mestrado) - Universidade de Taubaté, São Paulo, 2010.

STREET, Brian V. Literacy in theory and practice. Cambridge: Cambridge University Press, 1984.

STREET, Brian V. Academic Literacies approaches to Genre? Revista Brasileira de Linguística Aplicada, Belo Horizonte, v. 10, n. 2, 2010. Disponível em: $<$ http://goo.gl/uPlCyx >. Acesso em: 7 jul. 2017.

STREET, Brian V. Literacy and Multimodality. STIS Lecture: Inter-Disciplinary Seminars Laboratório Semiotec, da FALE/UFMG. Belo Horizonte, Faculdade de Letras, 2012.

SWALES, John M. Genre analysis: English in academic and researching settings. Cambridge: Cambridge University Press, 1990.

ZAVALA, Virgínia. Quem está dizendo isso?: letramento acadêmico, identidade e poder no ensino superior. In: VÓVIO, Cláudia Lemos; SITO, Luanda; DE GRANDE, Paula Baracat (Org.). Letramentos: rupturas deslocamentos e repercussões de pesquisas em linguística aplicada. Campinas, SP: Mercado de Letras, 2010. 